\title{
First Characterization and Description of Aspergillus Series Versicolores in French Bioaerosols
}

\author{
Antoine Géry ${ }^{1}$, Jean-Philippe Rioult ${ }^{1}$, Natacha Heutte ${ }^{2} \mathbb{D}$, Virginie Séguin ${ }^{1}$, Julie Bonhomme ${ }^{1,3}$ and \\ David Garon 1,*iD \\ 1 ToxEMAC-ABTE, Centre F. Baclesse, Unicaen and Unirouen, Normandie University, 14000 Caen, France; \\ antoine.gery@unicaen.fr (A.G.); jean-philippe.rioult@unicaen.fr (J.-P.R.); virginie.seguin@unicaen.fr (V.S.); \\ bonhomme-j@chu-caen.fr (J.B.) \\ 2 CETAPS, UFR Sciences et Techniques des Activités Physiques et Sportives Unirouen, Normandie University, \\ 76000 Rouen, France; natacha.heutte@univ-rouen.fr \\ 3 Service de Microbiologie, Centre Hospitalier Universitaire de Caen, 14000 Caen, France \\ * Correspondence: david.garon@unicaen.fr
}

check for updates

Citation: Géry, A.; Rioult, J.-P.; Heutte, N.; Séguin, V.; Bonhomme, J.; Garon, D. First Characterization and Description of Aspergillus Series Versicolores in French Bioaerosols. J. Fungi 2021, 7, 676. https://doi.org/ 10.3390/jof7080676

Academic Editors: Samantha C.

Karunarathna and Saowaluck

Tibpromma

Received: 30 July 2021

Accepted: 18 August 2021

Published: 21 August 2021

Publisher's Note: MDPI stays neutral with regard to jurisdictional claims in published maps and institutional affiliations.

Copyright: (c) 2021 by the authors. Licensee MDPI, Basel, Switzerland. This article is an open access article distributed under the terms and conditions of the Creative Commons Attribution (CC BY) license (https:// creativecommons.org/licenses/by/ $4.0 /)$.

\begin{abstract}
Air quality can be altered by fungal contaminants suspended in the air, forming bioaerosols. Aspergilli section Nidulantes series Versicolores are recurrent in bioaerosols and are mainly responsible for allergies and asthma aggravation. Phylogenetic studies recently identified 12 new species within this series. This study is the first to identify species of Aspergillus series Versicolores in French bioaerosols and to characterize them macroscopically, microscopically and molecularly. Bioaerosols were collected in a cancer treatment center, in contaminated homes and in agricultural environments. A total of 93 isolates were cultured on selective media, observed by optical microscopy and identified by ben $A$ amplification before sequencing. The field data (temperature and relative humidity) were statistically tested to explore the ecology of these species. Eight species were identified from bioaerosols: Aspergillus creber and $A$. jensenii, which represent more than $80 \%$ of the isolates, and A. protuberus, A. puulaauensis, A. sydowii, A. tabacinus, A. amoenus and A. fructus. Aspergilli series Versicolores are distributed differently depending on the sampling site and climatic determinants. Aspergillus protuberus was found in bioaerosols collected under significantly lower relative humidity $\left(p=3.899 \times 10^{-4}\right)$. Characterization and repartition of these isolates belonging to the Versicolores series constitute an important step to better assess exposure to fungal bioaerosols.
\end{abstract}

Keywords: mold; Versicolores series; bioaerosols

\section{Introduction}

Over the last decades, air quality has become a major public health issue, especially in industrialized countries. It is estimated that the population of these countries (including France) spends up to $90 \%$ of its time indoors [1,2], which has been exacerbated by the successive lockdowns related to the SARS-COV2 health crisis. According to the WHO [3], $30-50 \%$ of buildings in Europe have moisture problems that facilitate mold growth and bioaerosols' formation, leading to impaired indoor air quality [4]. These molds are visible in $14 \%$ to $20 \%$ of French housing [5]. This degradation of indoor air quality in homes has an impact on the quality of life and can lead to economic consequences estimated at 19 billion euros per year for France in terms of health expenses and renovation costs [6]. Some of these molds are known to aggravate asthma [7], cause allergies [8] and sometimes induce infections in immunocompromised individuals $[9,10]$. Some micromycetes are also capable of producing mycotoxins that may possess cytotoxic [11,12] and/or genotoxic properties $[13,14]$.

Molds of the genus Aspergillus belonging to the series Versicolores section Nidulantes are found in hypersaline water [15], in soil [16], in various foods and feeds [17] and in indoor environments, where they are estimated to be isolated from more than $70 \%$ of 
bioaerosols [18]. These species are especially known to cause allergies [19], aggravate asthma [20] and be involved in the sick building syndrome [21]. They are also found more sporadically as agents responsible for onychomycosis [22] or pulmonary aspergillosis [23]. More recently, their presence has been highlighted as an explanatory variable for various symptoms experienced by the inhabitants of mold-damaged homes, such as dizziness, fever, headache, itching or expectorations [18]. These are also known to produce sterigmatocystin [24], a mycotoxin involved in the aflatoxin biosynthetic pathway and which is recognized as a potential carcinogen by the IARC (group 2B) [25]. The species Aspergillus versicolor was considered until a few years ago as the most recurrent species of the Versicolores series present in bioaerosols. Recent phylogenetic studies [26,27] have led to taxonomic revisions that have revealed a total of 12 new species within the Versicolores series. Among these new species, Aspergillus creber is considered as the most frequent species and was misidentified as Aspergillus versicolor [28]. The few studies on the relative abundance of species of the Versicolores series in different matrices seem to confirm this hypothesis $[29,30]$. We also know that the different species in the Versicolores series do not all produce the same metabolites and are not as frequent in human pathology as each other [31].

In this study, we characterize and describe 93 environmental isolates of Aspergillus series Versicolores collected from French bioaerosols in order to evaluate their diversity and contribute to fungal exposure to Aspergillus series Versicolores.

\section{Material and Methods}

\subsection{Sampling}

Bioaerosols were collected indoors from a cancer treatment center (Centre François Baclesse, Caen, France) $(n=24)$ [32] and in contaminated homes $(n=65)$ [18,33], and outdoor in agricultural environments (silage and hay) $(n=4)[34,35]$. During collection, a Grimm particle counter (Model 1.108, Grimm Technologies, Inc., Douglasville, GA, USA) was used to measure temperature and relative humidity every $6 \mathrm{~s}$. The sampling of bioaerosols in contaminated homes was carried out during two different campaigns: the first one in Serpula lacrymans-damaged homes [33] and the second in mold-damaged homes [18].

Samples were cultured on Malt Extract Agar medium with $0.02 \%$ chloramphenicol (Cooper, Melun, France) (MEA+). Plates were incubated at $25^{\circ} \mathrm{C}$ and checked daily. Each fungal colony was isolated and purified on the same medium. All Aspergillus isolates belonging to the Versicolores series $(n=93)$ were stored on slant agar at $-4{ }^{\circ} \mathrm{C}$ and in a cryoprotective agent composed of sterile water (Fresenius Kabi AG, Bad Homburg, Germany) and $10 \%$ glycerol (Carlo Erba, Val-de-Reuil, France) at $-80{ }^{\circ} \mathrm{C}$ before characterization.

\subsection{Molecular Characterization}

DNA extraction was performed using a modified protocol of the Nucleospin ${ }^{\mathrm{TM}}$ Plant II kit (Macherey-Nagel, Duren, Germany). Fungal colony was introduced in a $2 \mathrm{~mL}$ microtube with glass beads. The microtube underwent two incubation cycles of $15 \mathrm{~min}$ at $80^{\circ} \mathrm{C}$ and then $15 \mathrm{~min}$ at $-80^{\circ} \mathrm{C}$. It was placed into a Qiagen Tissue Lyser with $400 \mu \mathrm{L}$ of lysis buffer PL1 (Macherey-Nagel, Duren, Germany) for $15 \mathrm{~min}$ at $20 \mathrm{~Hz}$, and incubated with $10 \mu \mathrm{L}$ of RNAse (Macherey-Nagel, Duren, Germany) and $20 \mu \mathrm{L}$ of proteinase $\mathrm{K}$ at $10 \mathrm{mg} / \mathrm{mL}$ (Sigma-Aldrich, St. Louis, MO, USA) at $65^{\circ} \mathrm{C}$ for $15 \mathrm{~min}$. Then, $400 \mu \mathrm{L}$ of chloroform (Sigma-Aldrich, St. Louis, MO, USA) was added to the mixture. The aqueous phase was recovered and extracted using the precipitation kit and washing buffer according to the protocol described by the supplier.

DNA was purified using the NucleoSpin gDNA Clean-up kit (Macherey-Nagel, Duren, Germany) following the instructions of the manufacturer. For each isolate, quantification and quality of purified DNA were realized using a NanoDrop 2000 spectrophotometer (Thermo Fisher Scientific, Waltham, MA, USA) [36]. 
Molecular characterization was performed by amplification of the beta-tubulin gene (benA) using Bt2a/Bt2b (5'-GGTAACCAAATCGGTGCTGCTTTC-3' / $5^{\prime}$-ACCCTCAGTGTA GTGACCCTTGGC- $3^{\prime}$ ) primers $[27,28]$. The end-point PCR program included: a hold stage at $94{ }^{\circ} \mathrm{C}$ for $5 \mathrm{~min}$, a PCR stage $\left(94^{\circ} \mathrm{C}\right.$ for $30 \mathrm{~s} ; 55^{\circ} \mathrm{C}$ for $45 \mathrm{~s} ; 72{ }^{\circ} \mathrm{C}$ during $90 \mathrm{~s}$ ) repeated for 35 cycles and another hold stage at $72{ }^{\circ} \mathrm{C}$ for $5 \mathrm{~min}$. PCR products were then sequenced by GATC (Eurofins, Hamburg, Germany). Sequences obtained were compared using BLAST (Basic Local Alignment Search Tool, NCBI) to the reference sequences of the 17 Aspergillus species of the Versicolores series (accession numbers: JN853946, JN853963, JN853980, EF652264, EF652273, KJ775086, LC000552, JN854007, KU613371, EF652284, JN853979, JN853970, EF652274, EF652302, JN853976, JN854003, EF652266) [27] and to the sequences of the CoreNucleotide, dbEST and dbGSS databases. Identification was considered reliable only by having a query cover $\geq 98 \%$ and a $\%$ ID $\geq 99 \%$.

\subsection{Macroscopic Characterization}

Macroscopic characterization was performed by culture of the Versicolores isolates on four different media: MEA without chloramphenicol (MEA), Czapek medium (CZ), Czapek Yeast Autolysate Agar (CYA25) and Czapek Yeast Extract Agar with 20\% sucrose (CY20S) at $25^{\circ} \mathrm{C}$ and on CYA at $37^{\circ} \mathrm{C}$ (CYA37). Conidia from 7- to 14-day-old cultures were mixed in soft agar $(0.2 \%$ agar $+0.05 \%$ Tween 80 (Sigma-Aldrich, St. Louis, MO, USA)). Each medium was inoculated in three points equidistant from the center with $2 \mu \mathrm{L}$ of this spore suspension. After 7 days of culture, the diameters, colors (given as hex color codes), textures and reliefs of the colonies were noted. After 14 days of culture, the presence or absence of exudate and diffusible pigment was noted [37,38].

\subsection{Microscopic Characterization}

Microscopic characterization was performed with an optical microscope Olympus CX31 (Olympus, Tokyo, Japan) after 10 days of culture on MEA, or on CY20S in case of low sporulation on MEA. For each isolate, the appearance and size of vesicles, the size of metulae, phialides and conidia, the texture of conidia, the color of fungal structures and the presence or absence of Hülle cells were specified [37,38].

\subsection{Statistical Analysis}

Descriptive statistics were calculated to provide information on isolates, and environmental data were subjected to the Mann-Whitney test. Only results at $p<0.05$ were considered statistically significant. All statistical analyses were realized using XLSTAT (Addinsoft, Paris, France).

\section{Results}

\subsection{Relative Abundance in French Bioaerosols}

Among all the mold species found in the different bioaerosols, Aspergilli series Versicolores were ranked fifth in bioaerosols from the cancer treatment center, first in Serpula lacrymans- and mold-damaged homes and third in agricultural environments, with concentrations ranging from $2.48 \mathrm{CFU} / \mathrm{m}^{3}$ to $3.44 \times 10^{5} \mathrm{CFU} / \mathrm{m}^{3}$ (mean: $9.30 \times 10^{3} \mathrm{CFU} / \mathrm{m}^{3}$ ). Aspergilli series Versicolores were associated with 109, 100 and 28 other fungal species in bioaerosols collected from the cancer treatment center, Serpula lacrymans- and molddamaged homes, and in agricultural environments, respectively. The most represented genera in all these environments were Aspergillus (A. fumigatus, A. niger, A. melleus, A. flavus, A. pseudoglaucus), Penicillium (P. chrysogenum, P. brevicompactum, P. crustosum) and Cladosporium (C. cladosporioides, C. herbarum, C. sphaerospermum) [18,32-34]. 
As shown in Figure 1, among all the isolates collected from French bioaerosols $(n=93)$, we were able to molecularly identify 8 species of the Versicolores series: Aspergillus creber (43\%) ranked first, followed by A. jensenii (40\%), A. protuberus (7\%), A. puulaauensis (4\%), A. sydowii ( $2 \%)$, A. tabacinus ( $2 \%)$, A. amoenus ( $1 \%$ ) and A. fructus (1\%). Bioaerosols collected in the cancer treatment center $(n=24)$ contained more $A$. jensenii $(58 \%)$, followed by A. protuberus $(25 \%)$, A. creber $(13 \%)$ and A. puulaauensis (4\%). A. protuberus was only found in bioaerosols collected in the cancer treatment center. Bioaerosols collected in Serpula lacrymans- and mold-damaged homes $(n=65)$ were mainly composed of $A$. creber $(57 \%)$ and A. jensenii (34\%). A. puulaauensis (5\%), A. sydowii (3\%) and A. amoenus ( $2 \%$ ) were also present. Among the four isolates obtained from bioaerosols collected in agricultural environments, we identified two isolates of $A$. tabacinus, one isolate of $A$. jensenii and one isolate of A. fructus. Aspergillus tabacinus and A. fructus were only found in bioaerosols collected in agricultural environments. A. jensenii was the only species found in all environments. We also observed a similar distribution of Versicolores species within the contaminated homes independently in the sampling campaign with the highest species richness.

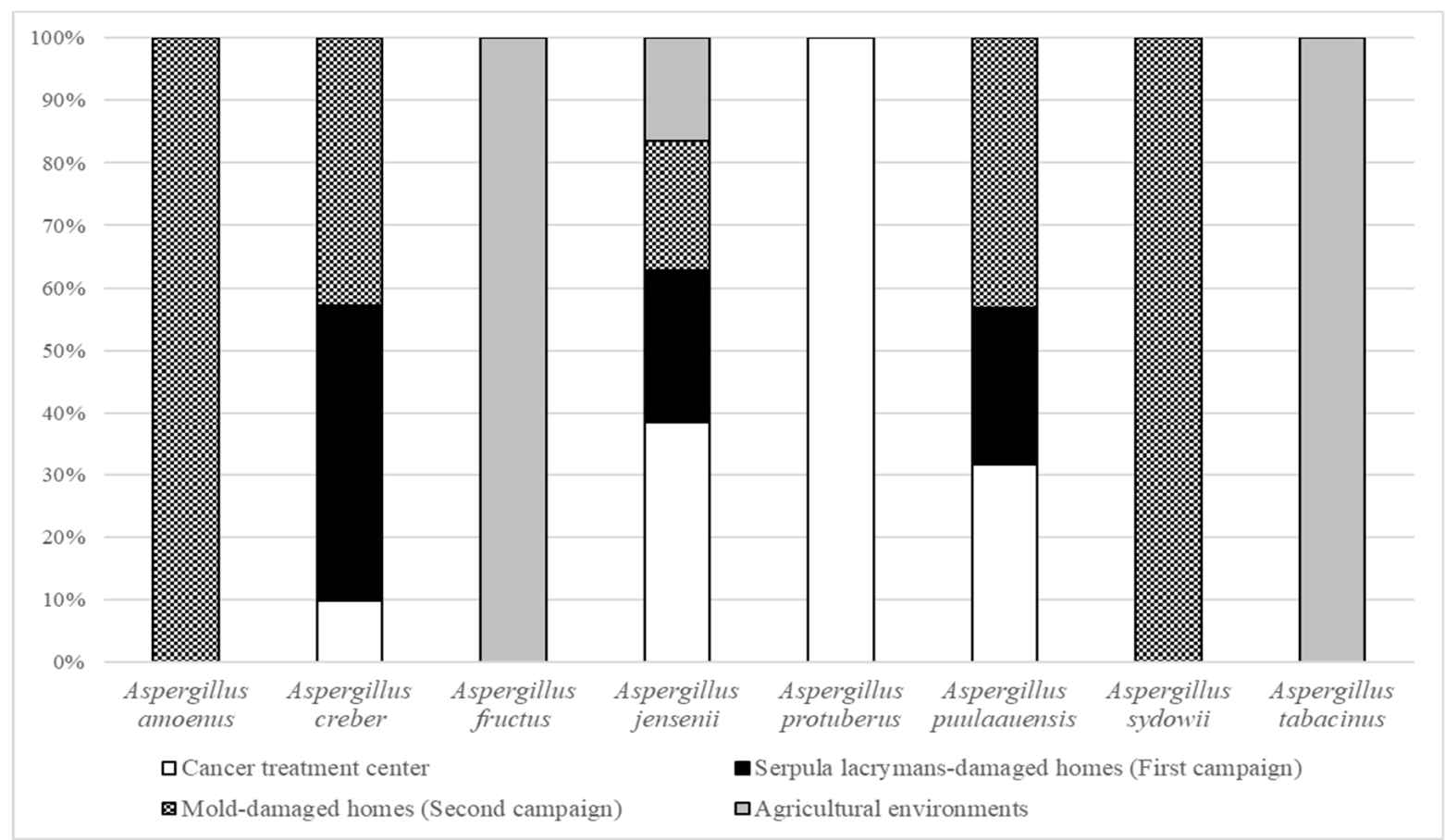

Figure 1. Relative abundances of Aspergillus species in the Versicolores series depending on bioaerosols' sampling location.

\subsection{Environmental Data}

The temperature measured in these different environments varied between 9.4 and $26.1{ }^{\circ} \mathrm{C}$, and the relative humidity between $23.8 \%$ and $74.3 \%$ (Table 1 ). Aspergillus amoenus, A. fructus and $A$. tabacinus were found in bioaerosols collected at low temperatures, while $A$. protuberus and A. sydowii were found in bioaerosols collected at higher temperatures. Aspergillus fructus, A. protuberus and A. tabacinus were also found in bioaerosols collected with low relative humidity, while A. amoenus, A. creber and A. sydowii were found in bioaerosols collected with high relative humidity. It should be noted that only Aspergillus protuberus was found in bioaerosols collected in the cancer treatment center with a significantly lower relative humidity than in bioaerosols not containing Aspergillus protuberus $\left(p=3.899 \times 10^{-4}\right)$. 
Table 1. Temperature and relative humidity measured during bioaerosols' collection.

\begin{tabular}{cccccccc}
\hline \multirow{2}{*}{ Species } & \multirow{2}{*}{$\mathbf{N}$} & \multicolumn{3}{c}{ Temperature $\left({ }^{\circ} \mathbf{C}\right)$} & \multicolumn{3}{c}{ Relative Humidity (\%) } \\
\cline { 2 - 8 } & & Min & Max & Mean & Min & Max & Mean \\
\hline A. amoenus & 1 & - & - & 19.9 & - & - & 66.1 \\
\hline A. creber & 40 & 9.4 & 26.1 & 20.7 & 23.8 & 74.3 & 57.5 \\
\hline A. fructus & 1 & - & - & 18.9 & - & - & 41.2 \\
\hline A. jensenii & 37 & 10.0 & 24.7 & 20.8 & 23.8 & 70.8 & 50.2 \\
\hline A. protuberus & 6 & 22.9 & 24.3 & 23.7 & 26.1 & 45.7 & 34.6 \\
\hline A. puulaauensis & 4 & 10.3 & 23.9 & 20.2 & 23.8 & 66.9 & 53.0 \\
\hline A. sydowii & 2 & 22.8 & 26.1 & 24.5 & 46.7 & 69.6 & 58.2 \\
\hline A. tabacinus & 2 & 18.4 & 20.8 & 19.6 & 32.4 & 49.2 & 40.8 \\
\hline
\end{tabular}

\subsection{Description of the Versicolores Series Species}

The culture on four selective media and the microscopic observations of ninety-three fungal isolates provide full details on these eight Aspergillus species in the series Versicolores (Table 2).

Table 2. Summary of microscopic characteristics.

\begin{tabular}{|c|c|c|c|c|c|c|c|c|}
\hline & $\begin{array}{c}\text { Aspergilllus } \\
\text { amoenus }\end{array}$ & $\begin{array}{c}\text { Aspergillus } \\
\text { creber }\end{array}$ & $\begin{array}{l}\text { Aspergillus } \\
\text { fructus }\end{array}$ & $\begin{array}{c}\text { Aspergillus } \\
\text { jensenii }\end{array}$ & $\begin{array}{l}\text { Aspergillus } \\
\text { protuberus }\end{array}$ & $\begin{array}{l}\text { Aspergillus } \\
\text { puulaauensis }\end{array}$ & $\begin{array}{c}\text { Aspergillus } \\
\text { sydowii }\end{array}$ & $\begin{array}{l}\text { Aspergillus } \\
\text { tabacinus }\end{array}$ \\
\hline $\begin{array}{l}\text { Conidial head } \\
(\mu \mathrm{m})\end{array}$ & $12-15$ & $\begin{array}{c}(3-) 5-13 \\
(-15)\end{array}$ & $12-13$ & (3-) 7-14 & $11-16$ & 9-15 & $6-12(-14)$ & 9-14 \\
\hline $\begin{array}{c}\text { Metulae } \\
(\mu \mathrm{m})\end{array}$ & $4-6$ & $\begin{array}{c}(3-) \text { 4-6 } \\
(-7)\end{array}$ & $4-6$ & $4-6(-7)$ & $3-5$ & $4-6$ & $4-7$ & $4-6$ \\
\hline $\begin{array}{l}\text { Phialides } \\
(\mu \mathrm{m})\end{array}$ & $5-6$ & $4-6(-8)$ & $5-6$ & $4-7(-8)$ & $4-7$ & $5-6$ & $5-7(-8)$ & $5-7$ \\
\hline $\begin{array}{l}\text { Conidia size } \\
(\mu \mathrm{m})\end{array}$ & $3-4$ & $2.5-4.5$ & $3-4$ & $\begin{array}{c}(2-) 3-4 \\
(-5)\end{array}$ & $2.5-3.5$ & $3-4.5$ & $3-4(-5)$ & $2.5-3.5$ \\
\hline $\begin{array}{l}\text { Conidial wall } \\
\text { ornementation }\end{array}$ & $\begin{array}{c}\text { finely or } \\
\text { distinctly } \\
\text { roughened }\end{array}$ & $\begin{array}{l}\text { finely or } \\
\text { distinctly } \\
\text { roughened }\end{array}$ & $\begin{array}{l}\text { smooth or } \\
\text { finely } \\
\text { roughened }\end{array}$ & $\begin{array}{l}\text { roughened } \\
\text { or finely } \\
\text { roughened }\end{array}$ & $\begin{array}{l}\text { smooth or } \\
\text { finely } \\
\text { roughened }\end{array}$ & roughened & $\begin{array}{l}\text { roughened to } \\
\text { distinctly } \\
\text { roughened }\end{array}$ & $\begin{array}{l}\text { distinctly } \\
\text { roughened }\end{array}$ \\
\hline Hülle cells & - & + & - & + & + & - & - & + \\
\hline Chlamydospores & - & - & - & + & - & - & + & - \\
\hline $\begin{array}{c}\text { Diminutive } \\
\text { conidial head }\end{array}$ & - & + & - & + & - & - & - & - \\
\hline
\end{tabular}

- absence; + presence.

\subsubsection{Aspergillus amoenus}

Description based on $n=1$ isolate (Figure 2).

\section{Macroscopic characteristics}

Colony diameters at 7 days, in mm, were: MEA 11-15, CZ 12-15, CY20S 23-27, CYA25 20-23 and CYA37 0-9.

On MEA, there were circular and flat colonies with an entire margin, conidia greyish green (from \#8 9066 to \#6d714d), mycelium was white to buff, reverse uncolored to yellow brown (\#c1a457), texture was velutinous to granular and there was no exudate or soluble pigment. On $\mathrm{CZ}$, there were circular and flat colonies flat with an entire margin, conidia were pale greyish green to greyish green (from \#d9cd97 to \#a8a975), mycelium were white to buff, reverse yellow brown (from \#c89847 to \#c59951), and texture was velutinous to granular; when present, exudate was uncolored or brownish orange to brownish red (from \#63512a to \#4b210f), and when present, soluble pigment was orange (\#ba8d2e). On CY20S, circular and umbonate colonies radially sulcate with an entire margin, conidia grey to greyish green (from \#a8a687 to \#9ea067), mycelium was white to 
buff, reverse brownish yellow to orange (from \#d1b236 to \#c29833), texture was velutinous and there was no exudate or soluble pigment. On CYA25, circular to irregular and flat colonies radially sulcate with an entire margin, conidia were dull green to greyish green (from \#a6b27a to \#989467), mycelium was white to buff, reverse brownish yellow to orange (from \#d1b236 to \#c29833), texture was velutinous to granular and exudate was uncolored to brownish orange (\#be985d); when present, soluble pigment was brownish orange (\#c59145). On CYA37, there were dense, convex and crateriform colonies with an entire margin, no conidiation with mycelium white to pale brown (\#cdb489), reverse brown (\#a27931), texture was velutinous and there was no exudate or soluble pigment.

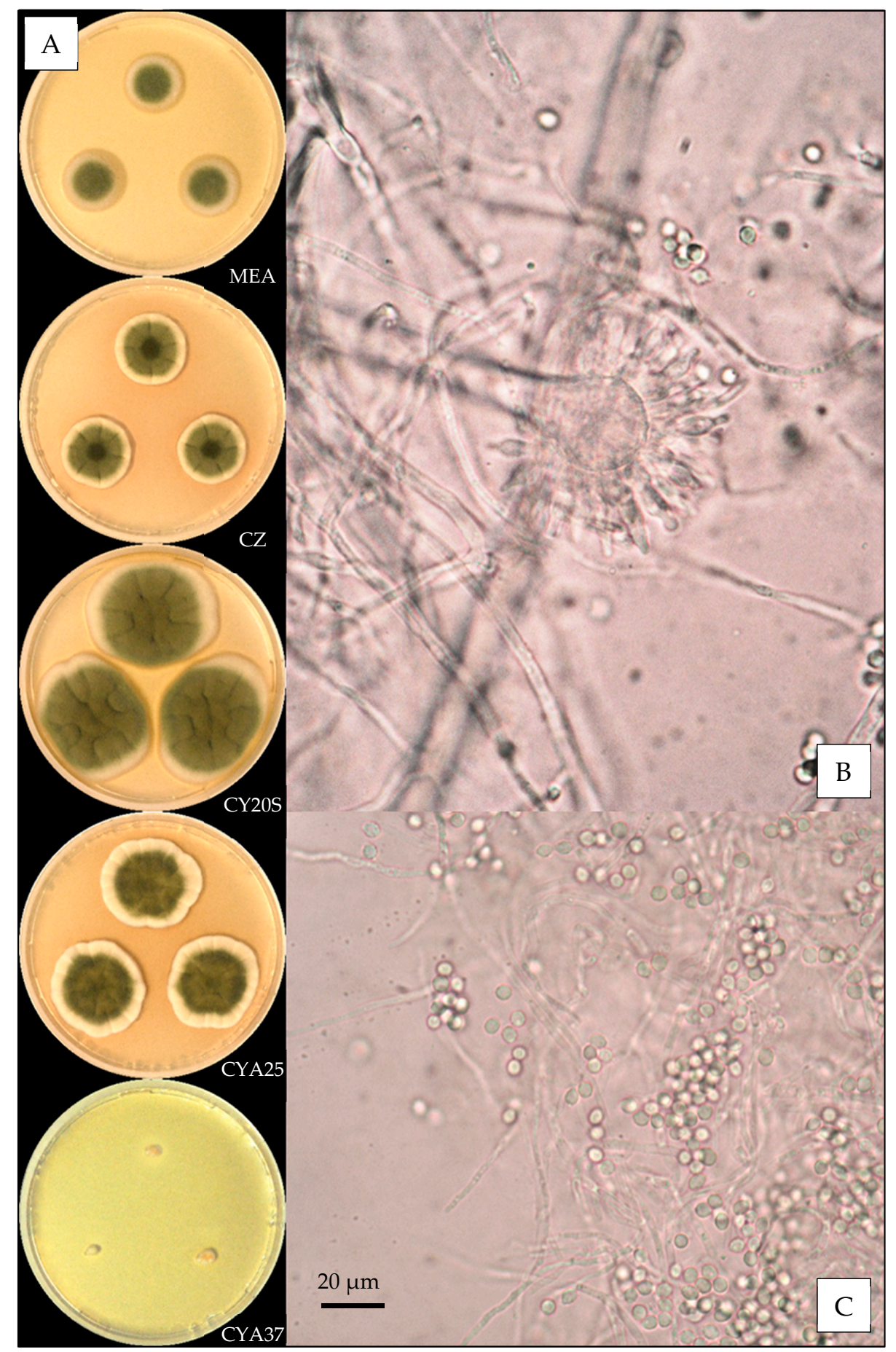

Figure 2. Aspergillus amoenus: (A) from top to bottom, colonies on MEA, CZ, CY20S, CYA25 and CYA37, 14 days. (B) Conidial head and (C) conidia $(1000 \times)$. 


\section{Microscopic characteristics}

Conidial heads radiate uncolored to greyish green vesicles expanding into pyriform vesicles $12-15 \mu \mathrm{m}$ in diameter, biseriate, metulae of $4-6 \mu \mathrm{m}$ covering all the vesicles and phialides of 5-6 $\mu \mathrm{m}$. No diminutive conidial head was observed for Aspergillus amoenus isolates. Conidia were $3-4 \mu \mathrm{m}$ in diameter, mostly globose to sub-globose, with finely or distinctly roughened walls. No globose Hülle cells or chlamydospores were observed.

\subsubsection{Aspergillus creber}

Description based on $n=40$ isolates (Figure 3).

Macroscopic characteristics

Colony diameters at 7 days, in mm, were: MEA 8-16 (-17), CZ (8-) 10-16 (-17), CY20S (18-) 19-26 (-28), CYA25 15-22 (-25) and CYA37 0-6 (-8).

On MEA, there circular and flat colonies with an entire margin, conidia yellow to dark green (from \#e3bc25 to \#52582a), mycelium was white to buff, reverse uncolored to orange (\#eea620), texture was velutinous to granular and there was no exudate or soluble pigment. On $\mathrm{CZ}$, there were circular and flat colonies with an entire margin, conidia were pale yellow or dull green to greyish green (\#ffdc61 or \#beb790 to \#77723c), mycelium was white to buff, reverse orange to brownish red (from \#be7329 to \#602909), texture was velutinous to granular; when present, exudate was yellow, brownish red, brown or black (\#ddbc72, \#5e1701, \# 804a0c or \#100c03) and soluble pigment was orange pink to dark pink (from \#dfa06b to \#b63346). On CY20S, circular and flat colonies sometimes radially sulcate with an entire margin, conidia were beige to greyish green (from \#e0bb74 to \#6b6023), mycelium was white or buff to brownish orange (\#905a21), reverse brownish orange to brownish red (from \#cc9700 to \#501a00), texture was velutinous; when present, rare exudate was yellow to brownish orange (\#eccc53 to \#894d20) and soluble pigment was dark red (\#a53000). On CYA25, circular and flat colonies often radially sulcate with an entire margin, conidia were yellow beige or dull green to greyish green (\#f2cb67 or \#646945 to \#76774e), mycelium was white to buff, reverse brownish orange (\#d57a18), texture was velutinous to granular; when present, exudate was brownish with shades from yellow to red or black (\#a3884a to \#501c01 or \#170d03), and when present, soluble pigment was dull orange to dark pink (\#e8a052 to \#8e1c24). On CYA37, when present, colonies were circular and flat with an entire margin, white to dull orange (\#db9441), reverse brownish yellow to brown (\#ca9329 to \#6c4b0a), texture was velutinous and there was no exudate; when present, soluble pigment was brownish orange (\#a46016).

Microscopic characteristics

Conidial heads radiate uncolored to greyish green vesicles expanding into pyriform vesicles of (3-) 5-13 (-15) $\mu \mathrm{m}$ in diameter, biseriate, metulae of (3-) 4-6 (-7) $\mu \mathrm{m}$ covering two thirds to all the vesicles and phialides of 4-6 (-8) $\mu \mathrm{m}$. Diminutive conidial heads were observed for Aspergillus creber isolates. Conidia were of $2.5-4.5 \mu \mathrm{m}$ in diameter, mostly globose to sub-globose, with finely or most of the time distinctly roughened walls. Hülle cells $(12-14 \mu \mathrm{m})$ were found, but no chlamydospores were observed. 


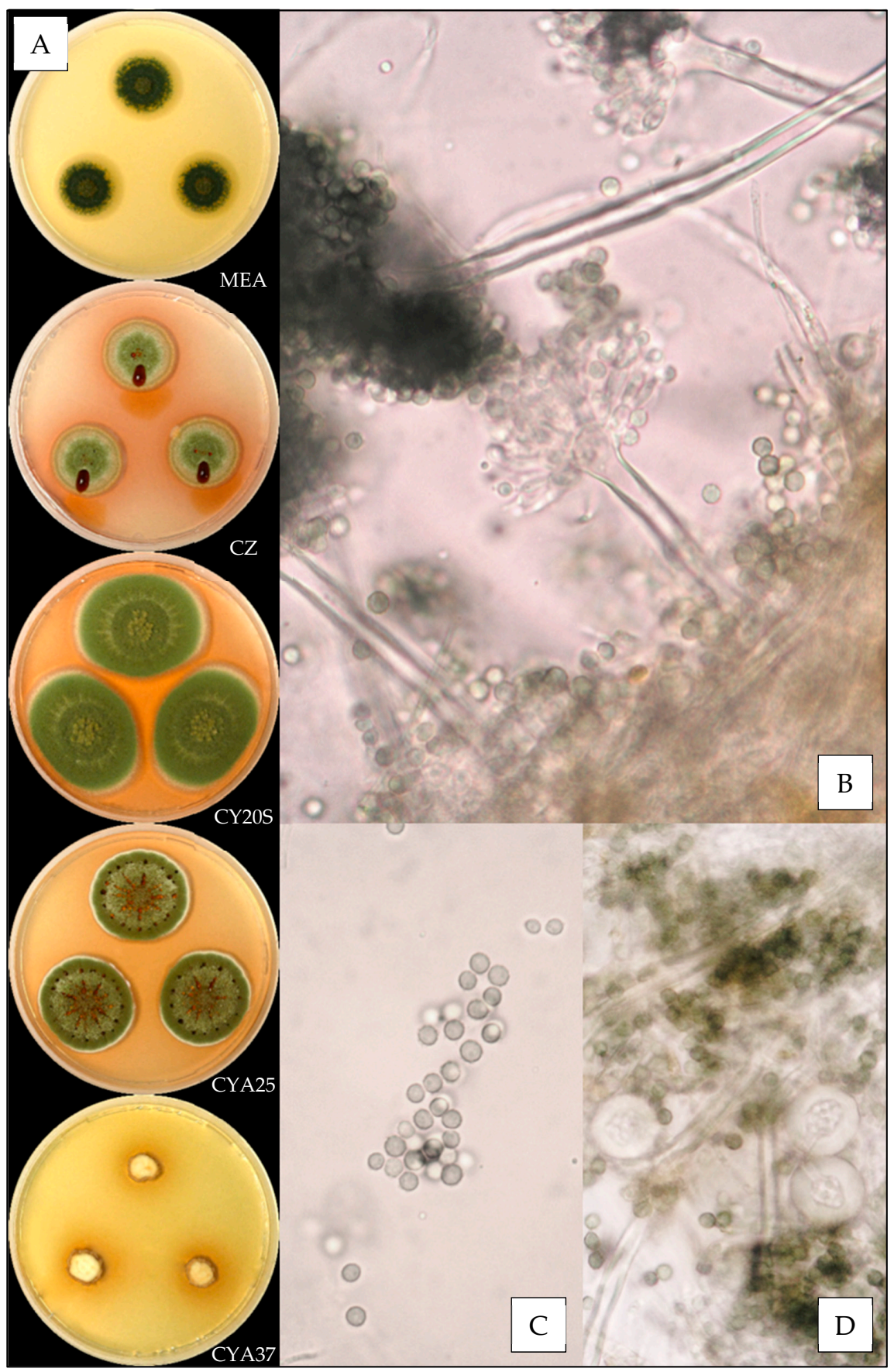

Figure 3. Aspergillus creber: (A) from top to bottom, colonies on MEA, CZ, CY20S, CYA25 and CYA37, 14 days. (B) Conidial head, (C) conidia and (D) globose Hülle cells $(1000 \times)$.

\subsubsection{Aspergillus fructus}

Description based on $n=1$ isolate (Figure 4).

\section{Macroscopic characteristics}

Colony diameters at 7 days, in mm, were: MEA 16-19, CZ 11-16, CY20S 25-30, CYA25 21-27 and CYA37 0-5.

On MEA, there were circular and flat colonies with an entire margin, conidia greyish green (\#5a6336), mycelium was white to buff, reverse uncolored, texture was granular and there was no exudate or soluble pigment. On $\mathrm{CZ}$, there were circular and flat colonies with an entire margin, conidia were greenish (\#ac9f37) with inconstant shades of dull pink (\#d1aa98), mycelium was white to buff, reverse brownish red (\#5c2e04), texture was velutinous to granular, exudate was greenish yellow or brownish orange to brownish red 
(\#bdaa30 or \#a77d00 to \#6a2e00) and there was no soluble pigment. On CY20S, circular and umbonate colonies sometimes radially sulcate with an entire margin, conidia were greenish (\#a89950), mycelium was white or buff, reverse dull orange (\#d3b072), texture was velutinous to granular and there was no exudate or soluble pigment. On CYA25, circular and flat colonies often radially sulcate with an entire margin, conidia were greyish green (\#78681d), mycelium was white to buff, reverse brownish orange (\#a35f00), texture was velutinous to granular; when present, exudate was brown (\#553400), and there was no soluble pigment. On CYA37, when present, colonies were white and wrinkled and flat with an entire margin, reverse brownish yellow (\#b59e73), texture was velutinous and there was no exudate or soluble pigment.

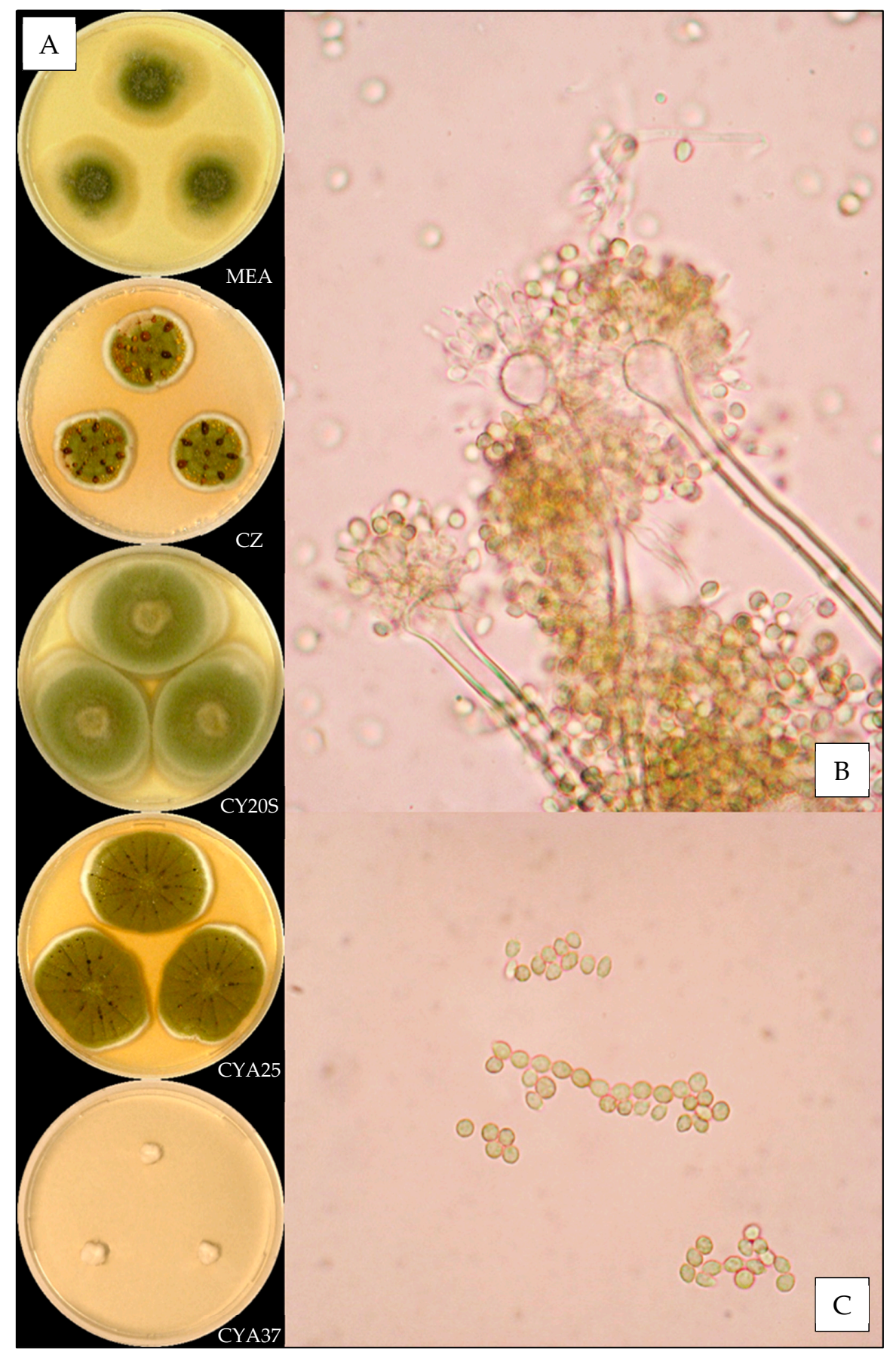

Figure 4. Aspergillus fructus: (A) from top to bottom, colonies on MEA, CZ, CY20S, CYA25 and CYA37, 14 days. (B) Conidial head and (C) conidia $(1000 \times)$. 


\section{Microscopic characteristics}

Conidial heads radiate uncolored to greyish green vesicles expanding into pyriform or spathulate vesicles of $12-13 \mu \mathrm{m}$ in diameter, biseriate, metulae of $4-6 \mu \mathrm{m}$ covering two thirds to all of the vesicles and phialides of 5-6 $\mu \mathrm{m}$. No diminutive conidial heads were observed for Aspergillus fructus isolates. Conidia of 3-4 $\mu \mathrm{m}$ in diameter were mostly globose or globose to sub-globose, with smooth or finely roughened walls. No Hülle cells or chlamydospores were observed.

\subsubsection{Aspergillus jensenii}

Description based on $n=37$ isolates (Figure 5).

Macroscopic characteristics

Colony diameters at 7 days, in mm, were: MEA (0-) 3-13 (-18), CZ (6-) 8-14 (-16), CY20S (11-) 16-25, CYA25 (8-) 12-18 (-20) and CYA37 0-5 (-8).

On MEA, there were circular and flat colonies with an entire margin, white to yellow (\#eec64e), mycelium was white, reverse uncolored to orange (\#f6b54f), texture was granular and there was no exudate or soluble pigment. On $\mathrm{CZ}$, there were circular and flat colonies with an entire margin, conidia were greenish (\#a5aa79), mycelium was white, reverse brownish pink to brownish red (\#d39f72 to \#68260f), texture was granular; when present, exudate was orange to brownish orange (\#fa6a00 to \#b9611a), and when present, soluble pigment was beige to brownish orange (\#e1b589 to \#c78107). On CY20S, circular and flat colonies radially sulcate with an entire margin, conidia were pale yellow to dull green (\#f2dd9e to \#a2a462), mycelium was white, reverse orange red (\#9c3d17), texture was velutinous and there was no exudate; when present, soluble pigment was orange red to brown (\#b54400 to \#341000). On CYA25, there were circular and flat colonies with an entire margin, conidia were greyish green (\#a7ac75) with non-constant pale orange shades (\#d9bd81), mycelium was white, reverse dark orange to brown (\#bf6327 to \#6f4215) and texture was velutinous; when present, exudate was orange pink to brown (\#fbbe82 to \#644533), and when present, soluble pigment was orange (\#c66927). On CYA37, when present, there were circular and convex white colonies with an entire margin, reverse brownish yellow (\#e0ad5a), texture was velutinous and there was no exudate or soluble pigment.

Microscopic characteristics

Conidial heads radiate uncolored to yellow orange vesicles expanding into pyriform or spathulate vesicles of (3-) 7-14 $\mu \mathrm{m}$ in diameter, biseriate, metulae of 4-6 (-7) $\mu \mathrm{m}$ covering two thirds to all of the vesicles and phialides of 4-7 (-8) $\mu \mathrm{m}$. Diminutive conidial heads were observed for Aspergillus jensenii isolates. Conidia of (2-) $3-4(-5) \mu \mathrm{m}$ in diameter were mostly globose or globose to sub-globose, with mostly roughened or finely roughened walls. Hülle cells $(12-16 \mu \mathrm{m})$ and chlamydospores were observed.

\subsubsection{Aspergillus protuberus}

Description based on $n=6$ isolates (Figure 6). 


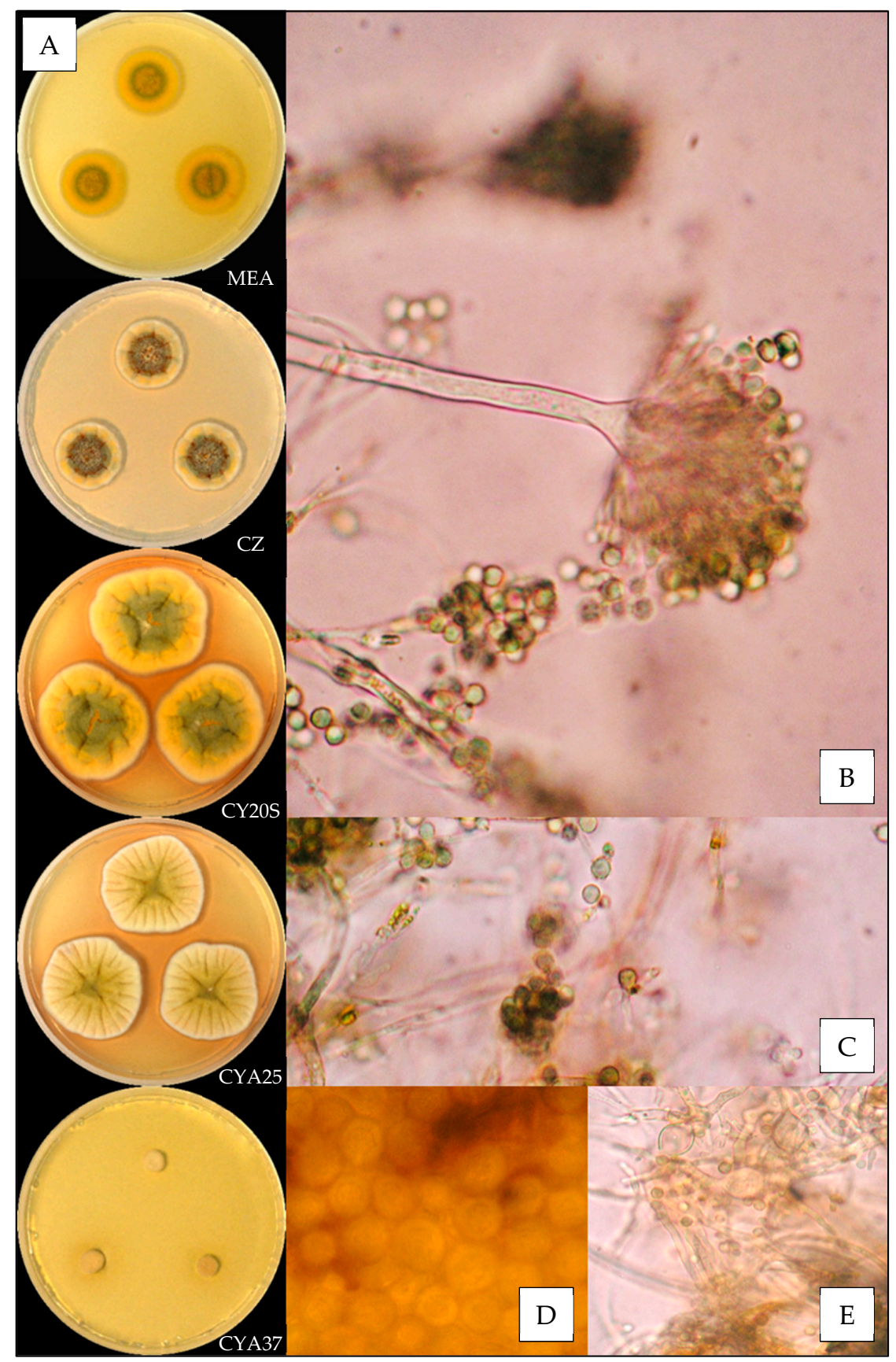

Figure 5. Aspergillus jensenii: (A) from top to bottom, colonies on MEA, CZ, CY20S, CYA25 and CYA37, 14 days. (B) Conidial head, (C) conidia, (D) globose Hülle cells and (E) chlamydospores $(1000 \times)$.

\section{Macroscopic characteristics}

Colony diameters at 7 days, in mm, were: MEA 8-18, CZ 5-19, CY20S 22-31, CYA25 1628 and CYA37 0-5 (-14).

On MEA, there were circular and flat colonies with an entire margin, conidia yellow to greyish green (\#e3bc63 to \#a0904d), mycelium was white to buff, reverse uncolored to orange (\#d5a553), texture was granular and there was no exudate or soluble pigment. On CZ, there were circular and flat colonies with an entire margin, conidia were greyish green or buff (\#ac9c56 or \#b08d61), mycelium was white, reverse brownish orange (\#6b350f), and texture was velutinous; when present, exudate was brown with orange or red shades (\#7d4e16 to \#531b00), and when present, soluble pigment was pink (\#e09a7a) or brownish orange (\#a56719). On CY20S, circular and flat or crateriform colonies radially sulcate with 
an entire margin, conidia were yellowish to greyish green (\#ddce61 to \#988c62), mycelium was white, reverse brownish orange (\#b8671c), texture was velutinous and there was no exudate; when present, soluble pigment was orange to brownish red (\#621400). On CYA25, circular and flat colonies often radially sulcate with an entire or undulate margin, conidia were brown to greyish green (from \#ae9166 to \#aaa581), mycelium was white to buff, reverse brownish orange to brownish red (from \#8d531a to \#4d2108), and texture was velutinous to granular; when present, exudate was brown (\#3e1800), and when present, soluble pigment was orange pink to brownish orange (from \#f5b67e to \#ac4b00). On CYA37, when present, colonies were dense and convex white to beige $(\# d 3 b 37 c)$ with an entire margin, reverse brownish yellow (\#c5a43b), texture was velutinous and there was no exudate or soluble pigment.

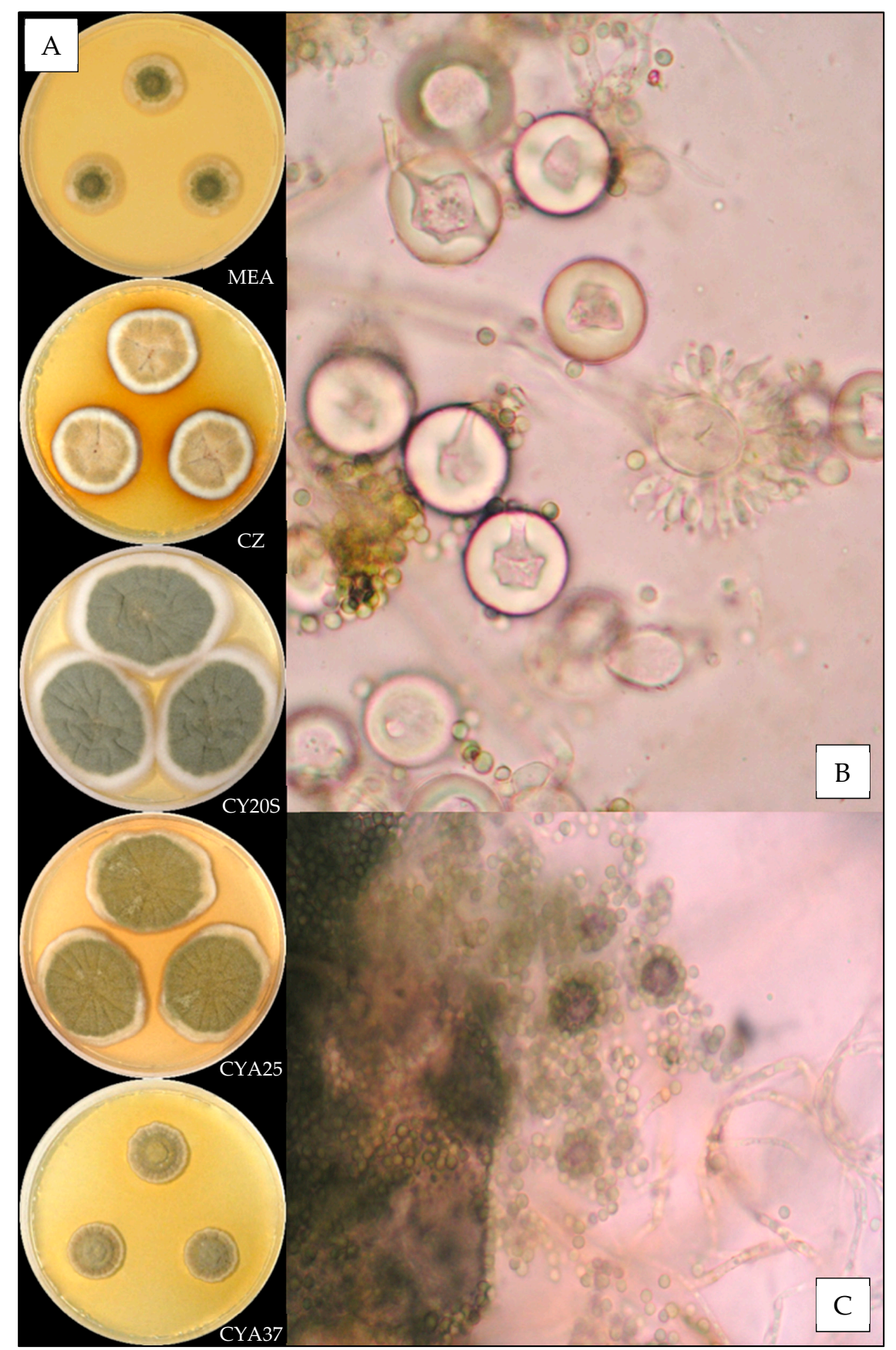

Figure 6. Aspergillus protuberus: (A) from top to bottom, colonies on MEA, CZ, CY20S, CYA25 and CYA37, 14 days. $($ B $)$ Conidial head and Hülle cells and $(\mathbf{C})$ conidia $(\times 1000)$. 


\section{Microscopic characteristics}

Conidial heads radiate uncolored to greyish green vesicles expanding into pyriform or spathulate vesicles of $11-16 \mu \mathrm{m}$ in diameter, biseriate, metulae of $3-5 \mu \mathrm{m}$ covering all of the vesicles and phialides of 4-7 $\mu \mathrm{m}$. No diminutive conidial heads were observed for Aspergillus protuberus isolates. Conidia of $2.5-3.5 \mu \mathrm{m}$ in diameter were mostly globose to sub-globose, with smooth or finely roughened walls. Hülle cells $(14 \mu \mathrm{m})$ were found but no chlamydospores were observed.

\subsubsection{Aspergillus puulaauensis}

Description based on $n=4$ isolates (Figure 7).

Macroscopic characteristics

Colony diameters at 7 days, in mm, were: MEA 11-14, CZ 11-15, CY20S 21-25, CYA25 17-19 and CYA37 0-5.

On MEA, there were circular and flat colonies with an entire margin, conidia were dull green to green (\#99ab87 to \#3f5f36), mycelium was white, reverse uncolored to orange (\#a85907), texture was granular and there was no exudate or soluble pigment. On CZ, there were circular and flat colonies with an entire margin, conidia were greyish green (\#b6a35b) with orange shades (\#daa74e), mycelium was white, reverse brown (\#5f412c), texture was granular, exudate was brownish orange (\#cc5c00) and soluble pigment was beige to orange (\#d78e69 to \#d17b19). On CY20S, circular and flat or colonies radially sulcate with an entire margin, conidia were greyish green (\#9e8d52), mycelium was white, reverse brownish orange (\#8d4d1f), texture was velutinous and there was no exudate; when present, soluble pigment was orange (\#db7314). On CYA25, circular and flat colonies radially sulcate with an entire margin, conidia were greyish green to dark green (from \#72815c to \#354532), mycelium was white, reverse brownish orange (\#7f4b1a), and texture was velutinous; when present, exudate was brownish orange to black (\#a64601 to \#0f0b00), and when present, soluble pigment was orange pink to pale orange (\#e3935d). On CYA37, when present, there were dense and convex white colonies with an entire margin, reverse uncolored, texture was velutinous and there was no exudate or soluble pigment.

\section{Microscopic characteristics}

Conidial heads radiate uncolored to greyish green vesicles expanding into pyriform vesicles of 9-15 $\mu \mathrm{m}$ in diameter, biseriate, metulae of 4-6 $\mu \mathrm{m}$ covering all of the vesicles and phialides of 5-6 $\mu \mathrm{m}$. No diminutive conidial heads were observed for Aspergillus puulaauensis isolates. Globose green conidia were of 3-4.5 $\mu \mathrm{m}$ in diameter, with roughened walls. No Hülle cells or chlamydospores were observed.

\subsubsection{Aspergillus sydowii}

Description based on $n=2$ isolates (Figure 8).

Macroscopic characteristics

Colony diameters at 7 days, in mm, were: MEA (11-) 14-21, CZ 12-22, CY20S (14-) 21-34, CYA25 16-26 (-31) and CYA37 0-18. 


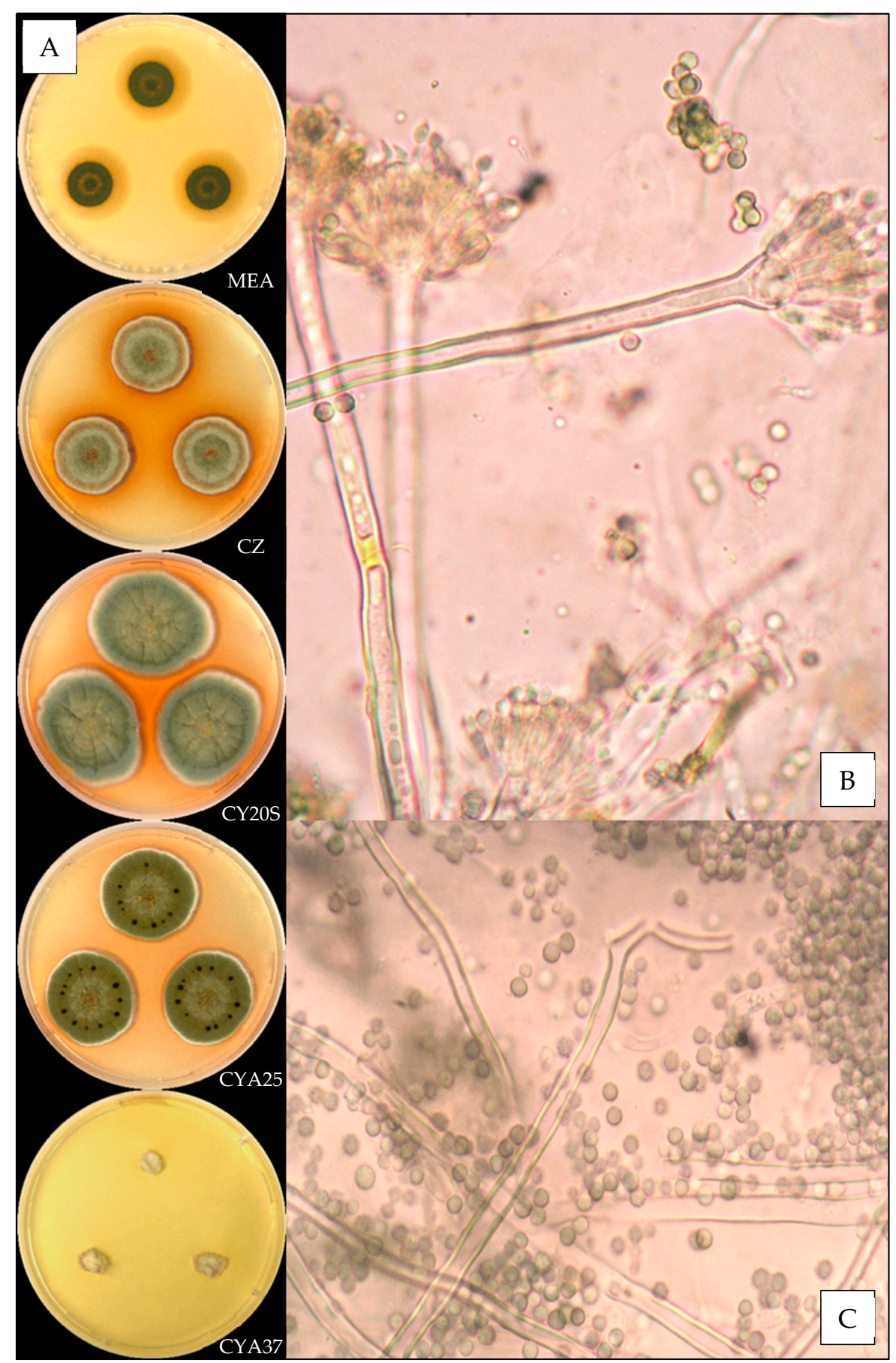

Figure 7. Aspergillus puulaauensis: (A) from top to bottom, colonies on MEA, CZ, CY20S, CYA25 and CYA37, 14 days. (B) Conidial head and $($ C) conidia $(1000 \times)$.

On MEA, there were circular and flat colonies with an entire margin, conidia were dark blue (\#353a40), mycelium was white, reverse uncolored, texture was velutinous to granular and there was no exudate; when present, soluble pigment was orange (\#c5792a). On $\mathrm{CZ}$, there were circular and flat colonies with an entire margin, conidia were blue green (\#404a45), mycelium was white, reverse brown (\#463b2a), and texture was granular; when present, exudate was yellowish to brownish red (\#cdac3f to \#732f00), and when present, soluble pigment was dull yellow to dull orange (\#e5c069 to \#c08c35). On CY20S, circular and flat or colonies sometimes radially sulcate with an entire margin, conidia were greyish blue (\#5f6a65), mycelium was white, reverse brownish orange (\#975f04), and texture velutinous; when present, exudate was black (\#12110c), and when present, 
soluble pigment was pale orange (\#d9ad4e). On CYA25, there were circular and flat colonies with an entire margin, conidia were greyish blue (\#81827a), mycelium was white, reverse brown (\#7e5631), and texture was velutinous; when present, exudate was brownish orange to brownish red (\#c0761b to \#762f00), and when present, soluble pigment was brownish yellow (\#c18919). On CYA37, colonies were dense and convex or wrinkled and crateriform with an entire margin, conidia were grey to dark grey (\#aca38a to \#554e33), sometimes with shades of brown (\#8d6d4a), reverse brownish black (\#1b1612), and texture velutinous; when present, exudate was brownish orange (\#93520e), and there was no soluble pigment.

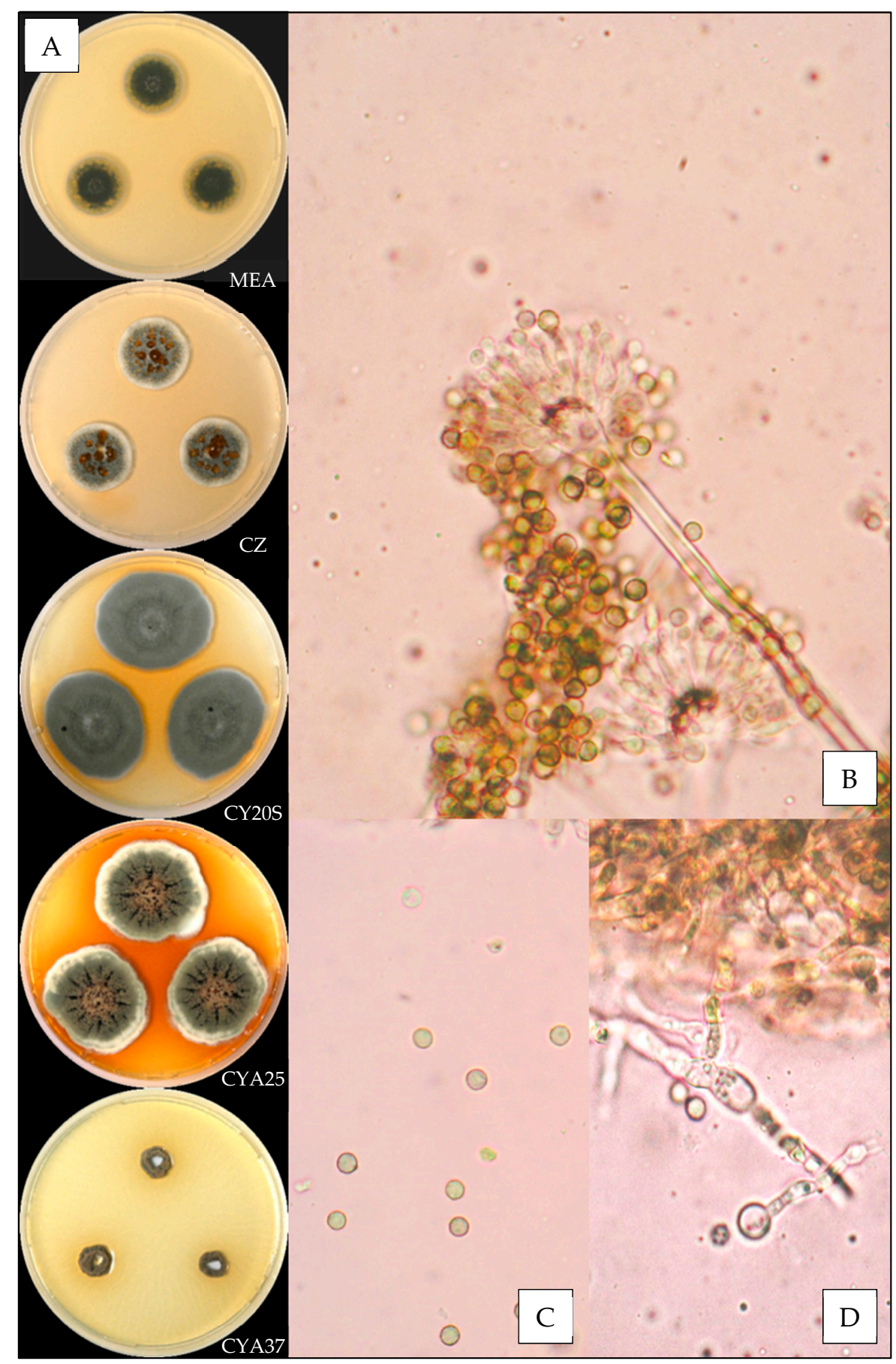

Figure 8. Aspergillus sydowii: (A) from top to bottom, colonies on MEA, CZ, CY20S, CYA25 and CYA37, 14 days. (B) Conidial head, (C) conidia and (D) chlamydospores $(1000 \times)$. 


\section{Microscopic characteristics}

Conidial heads radiate brown to greyish blue vesicles expanding into globose to spathulate vesicles of 6-12 (-14) $\mu \mathrm{m}$ in diameter, biseriate, metulae of 4-7 $\mu \mathrm{m}$ covering two thirds to all of the vesicles and phialides of 5-7 (-8) $\mu \mathrm{m}$. No diminutive conidial heads were observed for Aspergillus sydowii isolates. Globose conidia were of 3-4 (-5) $\mu \mathrm{m}$ in diameter, with roughened to distinctly roughened walls. Chlamydospores were found but no Hülle cells were observed.

\subsubsection{Aspergillus tabacinus}

Description based on $n=2$ isolates (Figure 9).

Macroscopic characteristics

Colony diameters at 7 days, in mm, were: MEA 13-16, CZ 15-20, CY20S 24-33, CYA25 23-25 and CYA37 0-3.

On MEA, there were circular and flat colonies with an entire margin, conidia were pale greyish green to dark greyish green (from \#b1a564 to \#565326), mycelium was white, reverse orange (\#ce7c11), texture was granular and there was no exudate; when present, soluble pigment was uncolored. On CZ, there were circular and flat colonies with an entire margin, conidia were dark beige to greyish green (\#b89656 to \#8a7429), mycelium was white to buff, reverse brownish orange (\#975409), and texture was velutinous to granular; when present, exudate was yellowish to dark brown (from \#d8c96e to \#221600), and when present, soluble pigment was pale red orange (\#b25128). On CY20S, circular and flat colonies often radially sulcate with an entire margin, conidia were greyish green (\#ab934d) with non-constant shades of orange (\#dea419), mycelium was white, reverse orange (\#e36a15), texture was velutinous and there was no exudate or soluble pigment. On CYA25, circular and flat colonies radially sulcate with an entire margin, conidia were dark beige to greyish green (\#e9bc73 to \#7d6b14), mycelium was white, reverse brownish orange (\#8f3d00), and texture was velutinous; when present, exudate was yellowish to dark brown (from \#cfac52 to \#0f0b02), and when present, soluble pigment was dull orange (\#b2621d). On CYA37, when present, colonies were circular and flat with an entire undulate margin, white, reverse brown (\#583306), texture was velutinous and there was no exudate or soluble pigment.

\section{Microscopic characteristics}

Conidial heads radiate uncolored to greyish green vesicles expanding into pyriform to spathulate vesicles of 9-14 $\mu \mathrm{m}$ in diameter, biseriate, metulae of $4-6 \mu \mathrm{m}$ covering all of the vesicles and phialides of 5-7 $\mu \mathrm{m}$. No diminutive conidial heads were observed for Aspergillus tabacinus isolates. Globose conidia were of 2.5-3.5 $\mu \mathrm{m}$ in diameter, with distinctly roughened walls. Hülle cells were found but no chlamydospores were observed. 


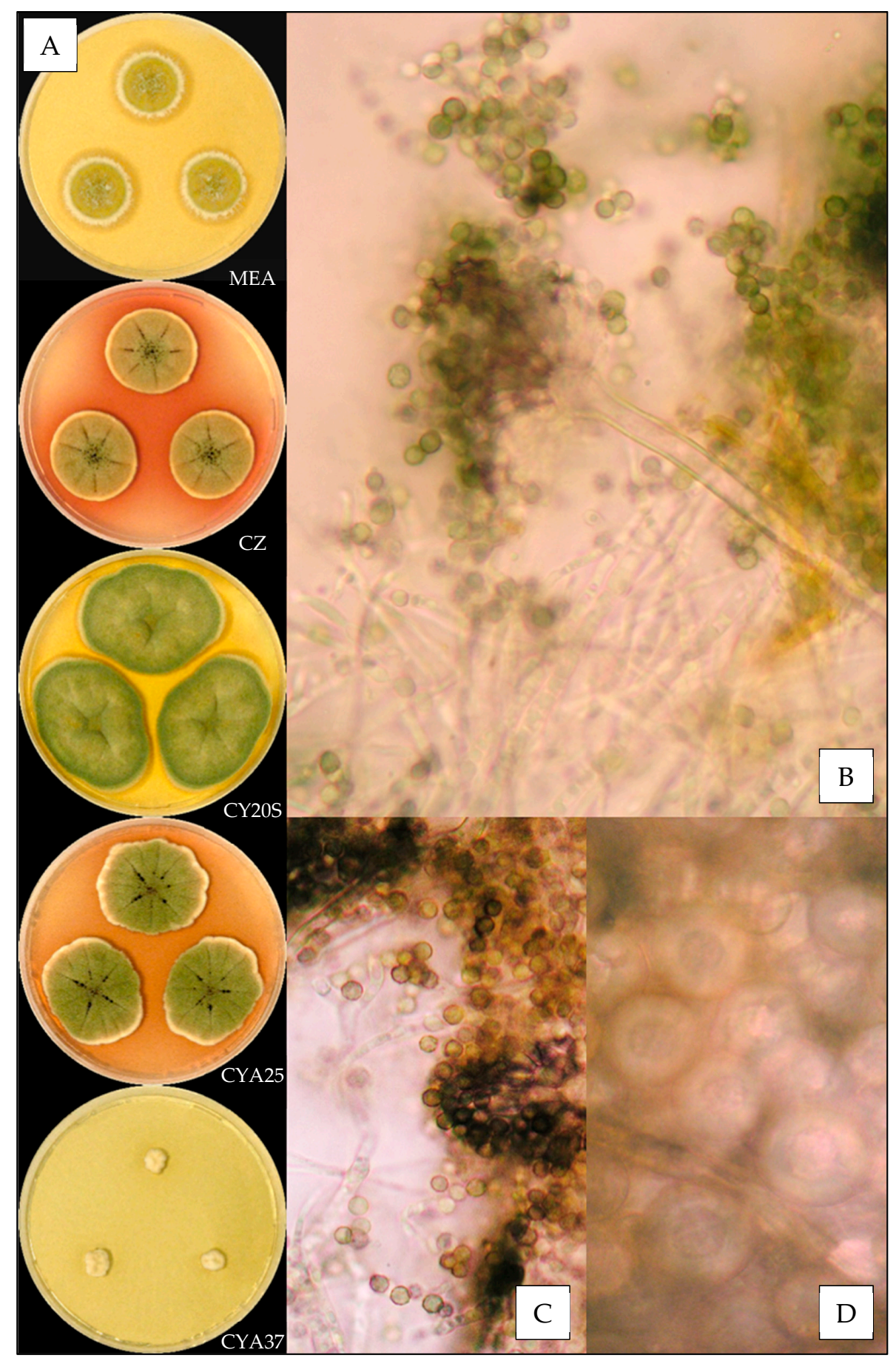

Figure 9. Aspergillus tabacinus: (A) from top to bottom, colonies on MEA, CZ, CY20S, CYA25 and CYA37, 14 days. (B) Conidial head, (C) conidia and (D) globose Hülle cells $(1000 \times)$.

\section{Discussion}

Ninety-three fungal isolates isolated from bioaerosols collected in a cancer treatment center, in contaminated homes and in agricultural environments were identified macroscopically and microscopically as belonging to Aspergillus series Versicolores. This study constitutes the first report on the distribution of these species in French bioaerosols. Molecular identification by ben $A$ gene amplification revealed 8 different species among the isolates found in our bioaerosols, which is one of the highest species richness reported to date. Indeed, other studies conducted on isolates collected from indoor environments (air and dust samples) identified by $\mathrm{CaM}$ gene amplification show that the species richness within 
the Versicolores series ranges from 3 (Aspergillus creber, A. jensenii and A. protuberus) to 11 species (A. creber, $A$. jensenii, $A$. puulaauensis, $A$. tennesseensis, $A$. venenatus, $A$. amoenus, A. fructus, A. griseoaurantiacus, A. pepii, A. protuberus and A. sydowii) [29,39]. Aspergillus creber and $A$. jensenii were the most frequently isolated species from French bioaerosols (83\% of isolates), which is consistent with studies on Aspergillus species belonging to the Versicolores series that always find these species, and especially with Jakšić et al.'s study, where these two species represent $62 \%$ of the isolates $[29,40]$. However, we did not find Aspergillus cvjetkovicii, A. griseoaurantiacus, A. pepii, A. tennesseensis or A. venenatus, which have been isolated from indoor air bioaerosols of the USA and Croatia $[26,29,40]$ but are more frequently found in various foods and feeds and in soil [26,30]. A. protuberus and $A$. puulaauensis are not as frequent but remain quite recurrent in indoor air and dust, as indicated by Micheluz et al. and Jakšić et al. [29,39]. Aspergillus protuberus was only found in bioaerosols collected in the cancer treatment center with significantly lower relative humidity in comparison to that observed for isolates of other species $\left(p=3.899 \times 10^{-4}\right)$. Nevertheless, no other study on the Versicolores series provides information on the climatic conditions during sampling, which does not allow to support if low relative humidity can be considered as a factor facilitating the growth of $A$. protuberus. Measurement of climatic conditions (temperature and relative humidity) during sampling should be systematically performed to provide additional data to explore the fungal ecology of this species. Moreover, all this information could be useful to determine if Aspergillus protuberus is an indicator of healthy homes, as opposed to A. creber, which is prevalent in damp indoor environments. Aspergillus sydowii was only isolated from two bioaerosols collected in contaminated homes, which confirms its presence at a rather low frequency in air compared to food matrices or in human pathology [26,30,31]. Aspergillus amoenus was isolated by Jurjevic et al. [26] from different sources (mammary gland, brined meat, Berberis sp. fruit) but also from indoor dust in Japan [30], which can explain why we found so few of them among all the collected isolates. This is the first time that Aspergillus tabacinus has been isolated from bioaerosols, whereas it is more frequently isolated from tobacco, brined meat or plants (maize) [26]. We also found one isolate of Aspergillus fructus which had never been identified in bioaerosols, even though it has already been recovered from dust of water-damaged and control homes in Croatia. However, this species seems more commonly identified from fruits [26]. Aspergillus versicolor stricto sensu was not found in our bioaerosols, which confirms the observations of Jurjevic et al. [26] and Kobayashi et al. [30], who only reported its presence in food products (dairy feed, rice and noodles).

We also reported the first observation of globose Hülle cells and the presence of diminutive conidial heads for Aspergillus creber, which were not described by Jurjevic et al. [26].

We observed, as previously described [26,38], an important intraspecific macroscopic polymorphism, which requires the use of sequencing to allow an identification at the molecular level for species of the Versicolores series. Nevertheless, the most recurrent species Aspergillus creber and A. jensenii have distinct macroscopic and microscopic aspects: $A$. creber has a grey-green appearance, while colonies, hyphae, conidial heads and conidia of $A$. jensenii are yellow-colored.

Further studies will be conducted to explore the metabolic and toxicological profiles of these different species. An analytical approach using HPLC-MS/MS will allow the identification and quantification of target metabolites, while cytotoxicity assays on lung cells will provide supplementary information on the toxicity of the isolates. All these data will allow a better knowledge of the species belonging to the series Versicolores and a better assessment of the exposure to bioaerosols containing these molds and their effects on health.

Author Contributions: Conceptualization, A.G., D.G. and J.B.; methodology, A.G., D.G., N.H. and J.-P.R.; investigation, A.G. and D.G.; writing-original draft preparation, A.G.; writing-review and editing, V.S., D.G., J.B., N.H. and J.-P.R.; supervision, D.G. and J.B. All authors have read and agreed to the published version of the manuscript. 
Funding: This research received no external funding.

Institutional Review Board Statement: Not applicable.

Informed Consent Statement: Not applicable.

Acknowledgments: ABTE-ToxEMAC is a member of the FHU (University Hospital Federation) RESPIRE: "Pathogènes, Environnement et Hôte: une approche integrative en santé respiratoire".

Conflicts of Interest: The authors declare no conflict of interest.

\section{References}

1. World Health Organization (Ed.) Indoor Air Pollutants: Exposure and Health Effects: Report on a WHO Meeting, Nördlingen, 8-11 June 1982; EURO Reports and Studies; World Health Organization, Regional Office for Europe: Copenhagen, Denmark, 1983; ISBN 978-92-890-1244-7.

2. Boulanger, G.; Bayeux, T.; Mandin, C.; Kirchner, S.; Vergriette, B.; Pernelet-Joly, V.; Kopp, P. Socio-Economic Costs of Indoor Air Pollution: A Tentative Estimation for Some Pollutants of Health Interest in France. Environ. Int. 2017, 104, 14-24. [CrossRef]

3. Who Regional Office For Europe. WHO Guidelines for Indoor Air Quality: Dampness and Mould; WHO Guidelines Approved by the Guidelines Review Committee; World Health Organization: Geneva, Switzerland, 2009; ISBN 978-92-890-4168-3.

4. Andersen, B.; Frisvad, J.C.; Søndergaard, I.; Rasmussen, I.S.; Larsen, L.S. Associations between Fungal Species and WaterDamaged Building Materials. Appl. Environ. Microbiol. 2011, 77, 4180-4188. [CrossRef]

5. ANSES. Moisissures Dans Le Bâti; ANSES Editions: Maisons-Alfort, France, 2016; p. 374.

6. Kopp, P.; Kirchner, S.; Boulanger, G.; Pernelet-Joly, V.; Bayeux, T.; Vergriette, B.; Mandin, C. Étude Exploratoire Du Coût SocioÉconomique Des Polluants de l'air Intérieur; ANSES Editions: Maisons-Alfort, France, 2014.

7. Tiotiu, A.I.; Novakova, P.; Nedeva, D.; Chong-Neto, H.J.; Novakova, S.; Steiropoulos, P.; Kowal, K. Impact of Air Pollution on Asthma Outcomes. Int. J. Environ. Res. Public. Health 2020, 17, 6212. [CrossRef]

8. Rick, E.; Woolnough, K.; Pashley, C.; Wardlaw, A. Allergic Fungal Airway Disease. J. Investig. Allergol. Clin. Immunol. 2016, 26, 344-354. [CrossRef]

9. Gletsou, E.; Ioannou, M.; Liakopoulos, V.; Tsiambas, E.; Ragos, V.; Stefanidis, I. Aspergillosis in Immunocompromised Patients with Haematological Malignancies. J. BUON Off. J. Balk. Union Oncol. 2018, 23, 7-10.

10. Spellberg, B.; Edwards, J.; Ibrahim, A. Novel Perspectives on Mucormycosis: Pathophysiology, Presentation, and Management. Clin. Microbiol. Rev. 2005, 18, 556-569. [CrossRef]

11. Bailey, J.R.; Breton, J.; Panic, G.; Cogan, T.A.; Bailey, M.; Swann, J.R.; Lee, M.R. The Mycotoxin Deoxynivalenol Significantly Alters the Function and Metabolism of Bovine Kidney Epithelial Cells In Vitro. Toxins 2019, 11, 554. [CrossRef]

12. Schmutz, C.; Cenk, E.; Marko, D. The Alternaria Mycotoxin Alternariol Triggers the Immune Response of IL-1 $\beta$-stimulated, Differentiated Caco-2 Cells. Mol. Nutr. Food Res. 2019, 63, 1900341. [CrossRef] [PubMed]

13. Benkerroum, N. Chronic and Acute Toxicities of Aflatoxins: Mechanisms of Action. Int. J. Environ. Res. Public Health 2020, 17, 423. [CrossRef] [PubMed]

14. Malir, F.; Ostry, V.; Pfohl-Leszkowicz, A.; Malir, J.; Toman, J. Ochratoxin A: 50 Years of Research. Toxins 2016, 8, 191. [CrossRef]

15. Kis-Papo, T.; Kirzhner, V.; Wasser, S.P.; Nevo, E. Evolution of Genomic Diversity and Sex at Extreme Environments: Fungal Life under Hypersaline Dead Sea Stress. Proc. Natl. Acad. Sci. USA 2003, 100, 14970-14975. [CrossRef]

16. Domsch, K.H.; Gams, W.; Anderson, T.H. Compendium of Soil Fungi; Academic Press: London, UK; New York, NY, USA, 1980; ISBN 978-0-12-220401-2.

17. Pitt, J.I.; Hocking, A.D. Fungi and Food Spoilage; Springer: New York, NY, USA, 2009; ISBN 978-0-387-92207-2.

18. Delanoë, A.; Heutte, N.; Gente, S.; Séguin, V.; Garon, D. Relationships between Exposure to Bioaerosols, Moldy Surface and Symptoms in French Mold-Damaged Homes. Atmosphere 2020, 11, 223. [CrossRef]

19. Vincent, M.; Percier, P.; De Prins, S.; Huygen, K.; Potemberg, G.; Muraille, E.; Romano, M.; Michel, O.; Denis, O. Investigation of Inflammatory and Allergic Responses to Common Mold Species: Results from in Vitro Experiments, from a Mouse Model of Asthma, and from a Group of Asthmatic Patients. Indoor Air 2017, 27, 933-945. [CrossRef] [PubMed]

20. Mintz-Cole, R.A.; Gibson, A.M.; Bass, S.A.; Budelsky, A.L.; Reponen, T.; Hershey, G.K.K. Dectin-1 and IL-17A Suppress Murine Asthma Induced by Aspergillus Versicolor but Not Cladosporium Cladosporioides Due to Differences in $\beta$-Glucan Surface Exposure. J. Immunol. 2012, 189, 3609-3617. [CrossRef] [PubMed]

21. Norbäck, D.; Hashim, J.H.; Cai, G.-H.; Hashim, Z.; Ali, F.; Bloom, E.; Larsson, L. Rhinitis, Ocular, Throat and Dermal Symptoms, Headache and Tiredness among Students in Schools from Johor Bahru, Malaysia: Associations with Fungal DNA and Mycotoxins in Classroom Dust. PLoS ONE 2016, 11, e0147996. [CrossRef]

22. Torres-Rodríguez, J.M.; Madrenys-Brunet, N.; Siddat, M.; López-Jodra, O.; Jimenez, T. Aspergillus Versicolor as Cause of Onychomycosis: Report of 12 Cases and Susceptibility Testing to Antifungal Drugs. J. Eur. Acad. Dermatol. Venereol. JEADV 1998, 11, 25-31. [CrossRef] [PubMed]

23. Charles, M.P. Invasive Pulmonary Aspergillosis Caused by Aspergillus Versicolor in a Patient on Mechanical Ventilation. Australas. Med. J. 2011, 4, 632-634. [CrossRef] 
24. Kubosaki, A.; Kobayashi, N.; Watanabe, M.; Yoshinari, T.; Takatori, K.; Kikuchi, Y.; Hara-Kudo, Y.; Terajima, J.; Sugita-Konishi, Y. A New Protocol for the Detection of Sterigmatocystin-Producing Aspergillus Section Versicolores Using a High Discrimination Polymerase. Biocontrol Sci. 2020, 25, 113-118. [CrossRef]

25. IARC Monographs On The Identification of Carcinogenic Hazards To Humans. Available online: https://monographs.iarc.who. int/ (accessed on 23 June 2021).

26. Jurjevic, Z.; Peterson, S.W.; Horn, B.W. Aspergillus Section Versicolores: Nine New Species and Multilocus DNA Sequence Based Phylogeny. IMA Fungus 2012, 3, 59-79. [CrossRef]

27. Houbraken, J.; Kocsubé, S.; Visagie, C.M.; Yilmaz, N.; Wang, X.-C.; Meijer, M.; Kraak, B.; Hubka, V.; Bensch, K.; Samson, R.A.; et al. Classification of Aspergillus, Penicillium, Talaromyces and Related Genera (Eurotiales): An Overview of Families, Genera, Subgenera, Sections, Series and Species. Stud. Mycol. 2020, 95, 5-169. [CrossRef]

28. Visagie, C.M.; Hirooka, Y.; Tanney, J.B.; Whitfield, E.; Mwange, K.; Meijer, M.; Amend, A.S.; Seifert, K.A.; Samson, R.A. Aspergillus, Penicillium and Talaromyces Isolated from House Dust Samples Collected around the World. Stud. Mycol. 2014, 78, 63-139. [CrossRef] [PubMed]

29. Jakšić, D.; Sertić, M.; Kifer, D.; Kocsubè, S.; Mornar Turk, A.; Nigović, B.; Šarkanj, B.; Krska, R.; Sulyok, M.; Šegvić Klarić, M. Fungi and Their Secondary Metabolites in Water-damaged Indoors after a Major Flood Event in Eastern Croatia. Indoor Air 2021, 31, 730-744. [CrossRef]

30. Kobayashi, N.; Kubosaki, A.; Takahashi, Y.; Yanai, M.; Konuma, R.; Uehara, S.; Chiba, T.; Watanabe, M.; Terajima, J.; Sugita-Konishi, Y. Distribution of Sterigmatocystin-Producing Aspergilli in Japan. Food Saf. 2018, 6, 67-73. [CrossRef] [PubMed]

31. Siqueira, J.P.Z.; Sutton, D.A.; García, D.; Gené, J.; Thomson, P.; Wiederhold, N.; Guarro, J. Species Diversity of Aspergillus Section Versicolores in Clinical Samples and Antifungal Susceptibility. Fungal Biol. 2016, 120, 1458-1467. [CrossRef] [PubMed]

32. Heutte, N.; André, V.; Bonhomme, J.; Dubos Arvis, C.; Kientz-Bouchart, V.; Lemarié, F.; Legendre, P.; Louis, M.-Y.; Madelaine, S.; Gente, S.; et al. Suivi de la Qualité de L'air Dans un Centre de Lutte Contre le Cancer: Evaluation et Caractérisation de L'exposition aux Contaminants Fongiques (Biohospitalair). Available online: https://www.hygienes.net/boutique/hygienes-2/ suivi-de-qualite-de-lair-centre-de-lutte-contre-cancer-evaluation-caracterisation-de-lexposition-aux-contaminants-fongiquesbiohospitalair / (accessed on 24 June 2021).

33. Pottier, D.; Andre, V.; Rioult, J.; Bourreau, A.; Duhamel, C.; Bouchart, V.K.; Richard, E.; Guibert, M.; Verite, P.; Garon, D. Airborne Molds and Mycotoxins in Serpula Lacrymans-Damaged Homes. Atmos. Pollut. Res. 2014, 5, 325-334. [CrossRef]

34. Lanier, C.; Richard, E.; Heutte, N.; Picquet, R.; Bouchart, V.; Garon, D. Airborne Molds and Mycotoxins Associated with Handling of Corn Silage and Oilseed Cakes in Agricultural Environment. Atmos. Environ. 2010, 44, 1980-1986. [CrossRef]

35. Séguin, V.; Lemauviel-Lavenant, S.; Garon, D.; Bouchart, V.; Gallard, Y.; Blanchet, B.; Diquelou, S.; Personeni, E.; Gauduchon, P.; Ourry, A. Effect of Agricultural and Environmental Factors on the Hay Characteristics Involved in Equine Respiratory Disease. Agric. Ecosyst. Environ. 2010, 135, 206-215. [CrossRef]

36. Desjardins, P.; Conklin, D. NanoDrop Microvolume Quantitation of Nucleic Acids. J. Vis. Exp. 2010, 45, 2565. [CrossRef]

37. Samson, R.A.; Visagie, C.M.; Houbraken, J.; Hong, S.-B.; Hubka, V.; Klaassen, C.H.W.; Perrone, G.; Seifert, K.A.; Susca, A.; Tanney, J.B.; et al. Phylogeny, Identification and Nomenclature of the Genus Aspergillus. Stud. Mycol. 2014, 78, 141-173. [CrossRef] [PubMed]

38. Klich, M.A. Identification of Common Aspergillus Species; Centraalbureau voor Schimmelcultures: Utrecht, The Netherlands, 2002.

39. Micheluz, A.; Sulyok, M.; Manente, S.; Krska, R.; Varese, G.C.; Ravagnan, G. Fungal Secondary Metabolite Analysis Applied to Cultural Heritage: The Case of a Contaminated Library in Venice. World Mycotoxin J. 2016, 9, 397-407. [CrossRef]

40. Jakšić, D.; Kocsubé, S.; Bencsik, O.; Kecskeméti, A.; Szekeres, A.; Vágvölgyi, C.; Varga, J.; Klarić, M.Š. Species Diversity and Cytotoxic Potency of Airborne Sterigmatocystin-Producing Aspergilli from the Section Versicolores. Sci. Total Environ. 2016, 562, 296-304. [CrossRef] 